\title{
Comparison of two strategies of peripheral blood progenitor cells induction with lenalidomide/dexamethasone in newly diagnosed multiple myeloma patients, followed by transplantation and lenalidomide maintenance treatment
}

Francisco Javier Capote Huelva ${ }^{1 *}$, Eduardo Ríos Herranz², Miguel Ángel Álvarez Rivas³, José Joaquín Ruíz Arredondo4, Antonio Alcalá Muñoz ${ }^{5}$, Alicia Bailén García ${ }^{6}$, José Luís Guzmán Zamudio7, Gemma Ramírez Ramírez ${ }^{8}$ and Antonio Fernández Jurado ${ }^{9}$

*Correspondence: fcapoteh@aehh.org

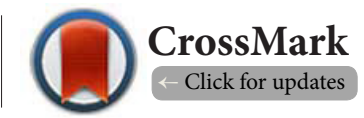

\author{
'Puerta del Mar Hospital (Cádiz). \\ ${ }^{2}$ Valme Hospital (Sevilla). \\ ${ }^{3}$ Reina Sofía Hospital (Córdoba). \\ ${ }^{4}$ Antequera Hospital (Málaga). \\ ${ }^{5}$ Jaén Complejo Hospitalario (Jaén). \\ ${ }^{6}$ Carlos Haya Hospital (Málaga). \\ ${ }^{7}$ Jerez Hospital (Jerez de la Frontera, Cádiz). \\ ${ }^{8}$ Virgen de la Victoria Hospital (Málaga). \\ `Juan Ramón Jiménez Hospital (Huelva).
}

\begin{abstract}
Background: The most common therapy in young multiple myeloma patients include induction, mobilization, collection and graft of peripheral blood stem cells. The present phase 2, multi-center, randomized study was designed to compare the results after four ( $\operatorname{arm} \mathrm{A})$ and two (arm B) cycles of induction with lenalidomide plus dexamethasone as first line of treatment. The main aim of the study was to compare the number of collected stem cells for transplant between both arms.

Findings: Of the 31 initially included patients, 23 patients were evaluable, 11 and 12 patients in arm A and $\mathrm{B}$, respectively. After induction and mobilization a non-significantly different mean of 4.30 x $106 \mathrm{CD} 34+$ cells $/ \mathrm{kg}$ in arm A and $4.79 \times 106 \mathrm{CD} 34+$ cells $/ \mathrm{kg}$ in arm B were obtained ( $\mathrm{p}=0.460)$, respectively. Although a lower number of CD34+ cells were obtained compared with previous studies, it was a sufficient yield for transplantation. The overall response rate was $94.8 \%$ and $93.9 \%$ at induction and at autologous stem cell transplantation (ASCT), respectively. No differences were observed between arms in the response rate, which was similar to that reported in previous studies. On the other hand, to sufficiently contrast differences in the overall survival and the progression-free survival endpoints, this study suffered from the limitation of the low number of patients followed.
\end{abstract}

Conclusion: Our study confirmed the existing results about grafts quality obtained with lenalidomide and the effectiveness of mobilization with cyclophosphamide and granulocyte colony stimulating factor (G-CSF), although wider randomized studies should confirm the extension and implication of the observations related to response rate, overall survival and progression-free survival.

Keywords: Multiple myeloma, lenalidomide, dexamethasone, peripheral blood stem cells, autologous transplantation, stem cell mobilization

\section{Introduction}

Multiple myeloma (MM) is a malignant neoplasm of plasma cells that accumulate in bone marrow, leading to bone mar- row failure, bone destruction, hypercalcemia, and renal failure. MM accounts for $1 \%$ of all malignant diseases and $15 \%$ of the haematological malignancies [1]. The outcome for patients with 
Huelva et al. Hematology and Leukemia 2018,

http://www.hoajonline.com/journals/pdf/2052-434X-6-4.pdf

doi: $10.7243 / 2052-434 X-6-4$

MM has improved over the last years and various therapies, now, are available and the therapy is tailored to each patient; in young MM patients consists of the induction treatment with different drugs for 3-6 months, followed by high-dose chemotherapy and autologous stem cell transplantation (ASCT) $[2,3]$. Lenalidomide plus dexamethasone is an option for pretransplant induction therapy [4].

The number of $\mathrm{CD} 34^{+}$cells collected for ASCT depends on numerous factors: number of expected transplants (traditionally, the target for $\mathrm{CD}_{3} 4^{+}$cell collection for a single ASCT has been 4 to $6 \times 10^{6} \mathrm{CD}^{4} 4^{+} / \mathrm{kg}$ ); age (it is expected a decreasing yield with advancing age); patient performance status (patients with good performance status may undergo transplantation up into their mid-70s); comorbidities (i.e. marrow disease is associated with lower number of $\mathrm{CD} 34^{+}$cells collected), etc. [5]

The main objective of this study was to compare the total number of peripheral blood stem cell (PBSC) collected after 2 or 4 induction cycles with lenalidomide plus dexamethasone.

\section{Patients and methods \\ Study design and treatment}

This was a phase 2 , multi-center, controlled against alternative experimental treatment, randomized (1:1) and stratified (according to age and International Staging System [ISS] stage [6]) clinical trial.

Eligible patients were candidates for ASCT with symptomatic MM who were not previously treated and with Eastern Cooperative Oncology Group (ECOG) score $\leq 2$ [7]. The main exclusion criteria were peripheral neuropathy grade above 2 , severe renal failure, history of active malignancy during the past 3 years (with exception of skin, cervical or breast carcinoma), hypersensitivity to thalidomide or to dexamethasone, and primary amyloidosis.

The population was randomized in two different treatment arms. Arm A patients received four treatment cycles (lenalidomide $25 \mathrm{mg} /$ day on days 1 to 21 of each 28-day cycle and dexamethasone $40 \mathrm{mg} /$ day on days 1, 8, 15 and 22 each 28-day cycle) and the mobilization and apheresis of hematopoietic cells from bone marrow was performed after the four cycles. Arm B patients received two treatment cycles with the same treatment schedule as arm $A$ and the mobilization and apheresis was realized after this two cycles, afterwards two more cycles were administered.

The PBSC mobilization was performed with cyclophosphamide $1.5 \mathrm{~g} / \mathrm{m}^{2}$ on day 1 and granulocyte colony stimulating factor (G-CSF) $10 \mu \mathrm{g} / \mathrm{kg} /$ day on day 3 until completion of PBSC collection between days 10 and 13, approximately. The apheresis was performed from day 10 to about day 13. In both arms, high dose chemotherapy treatment with melphalan $200 \mathrm{mg} / \mathrm{m}^{2}$ was carried out. ASCT was performed 48 hours after chemotherapy.

Patients who achieved at least one partial response received maintenance therapy with lenalidomide $10 \mathrm{mg} /$ day for 21 days in each 28-day cycle and acetylsalicylic acid $10 \mathrm{mg} /$ day at 3 months of autotransplantation. Maintenance treatment was maintained until disease progression, unacceptable toxicity or until the patient decided not to participate in the study.

\section{Statistical analysis}

Qualitative variables were described by frequency and percentages based on the size of the non-missing sample. The quantitative variables were obtained through the non-missing sample size (n), mean, standard deviation (SD), confidence interval $(\mathrm{Cl})$, median, quartile $1(\mathrm{Q} 1)$, quartile $3(\mathrm{Q} 3)$, maximum and minimum. Missing data were not imputed.

\section{Results}

\section{Disposition, baseline demographics and disease char-} acteristics

The study enrolled a total of 31 patients and, finally, 23 patients were included in the per protocol population (arm A: 11 patients; arm B: 12 patients). The reasons to be withdrawn were: 1 selection fail, 6 interrupted interventions and 1 principal response assessment not available. Table 1 shows the

Table 1. Demographics, baseline and clinical characteristics of patients.

\begin{tabular}{|c|c|c|c|}
\hline & $\begin{array}{l}\operatorname{Arm} A \\
(n=11)\end{array}$ & $\begin{array}{l}\text { Arm B } \\
(n=12)\end{array}$ & $\begin{array}{l}\text { Total } \\
\text { population } \\
(\mathrm{n}=23)\end{array}$ \\
\hline Sex, Male, n (\%) & $5(45.5)$ & $8(66.7)$ & $13(56.5)$ \\
\hline Age, years, mean (SD) & $55.1(6.8)$ & $55.7(11.3)$ & $55.4(9.2)$ \\
\hline Weight, Kg, mean (SD) & $81.4(13.1)$ & $77.5(13.2)$ & $79.3(13.0)$ \\
\hline \multicolumn{4}{|l|}{ ISS prognostic index, $\mathbf{n}(\%)$} \\
\hline I & $4(36.4)$ & $8(66.7)$ & $12(52.2)$ \\
\hline II & $3(27.3)$ & $4(33.3)$ & $7(30.4)$ \\
\hline III & $4(36.4)$ & $0(0.0)$ & $4(17.4)$ \\
\hline \multicolumn{4}{|l|}{ ISS classification, $\mathbf{n}(\%)$} \\
\hline I & $0(0.0)$ & $2(16.6)$ & $2(8.7)$ \\
\hline II & $4(36.4)$ & $5(41.7)$ & $9(39.2)$ \\
\hline III & $6(54.5)$ & $5(41.7)$ & $11(47.8)$ \\
\hline Unknown & $1(9.1)$ & $0(0.0)$ & $1(4.3)$ \\
\hline \multicolumn{4}{|l|}{ ECOG Performance Status, $\mathbf{n}(\%)$} \\
\hline 0 & $6(54.5)$ & $4(33.3)$ & $10(43.5)$ \\
\hline 1 & $3(27.3)$ & $5(41.7)$ & $8(34.8)$ \\
\hline 2 & $2(18.2)$ & $2(16.7)$ & $4(17.4)$ \\
\hline Unknown & $0(0.0)$ & $1(8.3)$ & $1(4.3)$ \\
\hline Abnormal ECG, n (\%) & $1(11.1)^{*}$ & $2(22.2)^{\dagger}$ & $3(16.7)$ \\
\hline Cytogenetic test available, $\mathrm{n}(\%)$ & $7(83.3)$ & $8(66.6)$ & $15(65.2)$ \\
\hline chromosome 13 deletion, $\mathrm{n}(\%)$ & $1(14.3)$ & $2(25.0)$ & $3(20.0)$ \\
\hline chromosome 17 deletion, $\mathrm{n}(\%)$ & $0(0.0)$ & $2(25.0)$ & $2(13.3)$ \\
\hline Translocation (4:14), n (\%) & $0(0.0)$ & $0(0.0)$ & $0(0.0)$ \\
\hline Translocation (4:16), n (\%) & $1(14.3)$ & $1(14.3)$ & $2(13.3)$ \\
\hline
\end{tabular}

$\mathrm{SD}=$ standard deviation; ISS= International Staging System; ECOG= Eastern Cooperative Oncology Group; ECG= Electrocardiogram

${ }^{\star}$ Mitral insufficiency

$\dagger 1$ right bundle branch block (RBBB) and 1 incomplete RBBB 
Huelva et al. Hematology and Leukemia 2018,

main demographics and disease characteristics.

\section{Obtaining CD34 ${ }^{+}$cells}

A mean number $( \pm S D)$ of $2.3( \pm 0.9)$ and $1.5( \pm 0.8)$ apheresis was performed in arm A and arm B, respectively. The median (Min-Max) PBSC collected was $4.30 \times 10^{6} \mathrm{CD}^{4} 4^{+}$cells $/ \mathrm{kg}(2.3-$ 8.2) and $4.79 \times 10^{6} \mathrm{CD} 34^{+}$cells $/ \mathrm{kg}(2.27-13.6)$ in arm $\mathrm{A}$ and arm $B$, respectively (Figure 1). There was no statistically significant difference between both arms $(p=0.460)$.

\section{Response rate}

The response rate (RR) was assessed with International Myeloma Working Group (IMWG) criteria at the end of induction and ASCT phases (Figure 2). At induction, the overall RR was 94.8\%; with stringent complete remission ( $\mathrm{s} C \mathrm{CR})$, complete remission $(\mathrm{CR})$, very good partial response (VGPR) and partial response (PR) of $0.0 \%, 15.8 \%, 21.1 \%$ and $57.9 \%$, respectively. At ASCT, the overall RR was $93.9 \%$; with sCR, CR, VGPR and PR of $25.0 \%$, $31.3 \%, 31.3 \%$ and $6.3 \%$, respectively. No significant differences in RR were observed between both arms at any time.

\section{Overall Survival and Progression-Free Survival}

For arm A, the median $(95 \% \mathrm{Cl})$ overall survival (OS) was 17.3 months (14.7-19.8) and the median $(95 \% \mathrm{Cl})$ progression-free survival (PFS) was 19.1 months (14.9-23.4). The median OS and PFS were not reached for arm $B$ due to the low number of events and limited follow-up in this cohort ( $p$ long Rank test $=0.005$ and 0.013 , respectively).

\section{Safety}

There were a total of 11 severe adverse events reported, including 5 treatment-related events ( 1 back pain, 1 neutropenia, 1
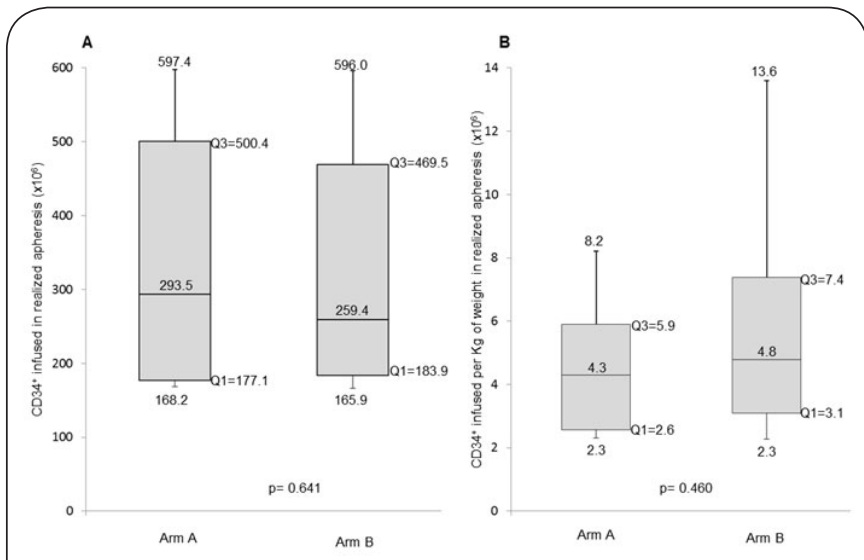

Figure 1. Outcomes of infused $\mathrm{CD}^{+} 4^{+}$cells in carried out apheresis.

(A) Whole number of infused CD $34^{+}$cells. Data were expressed as median, Q1, Q3 minimum and maximum (B). Total number of infused CD34+ cells per $\mathrm{kg}$ of weight. Data expressed as median, Q1, Q3, minimum and maximum $\mathrm{P}$-value of a nonparametric test, Mann-Whitney U test.

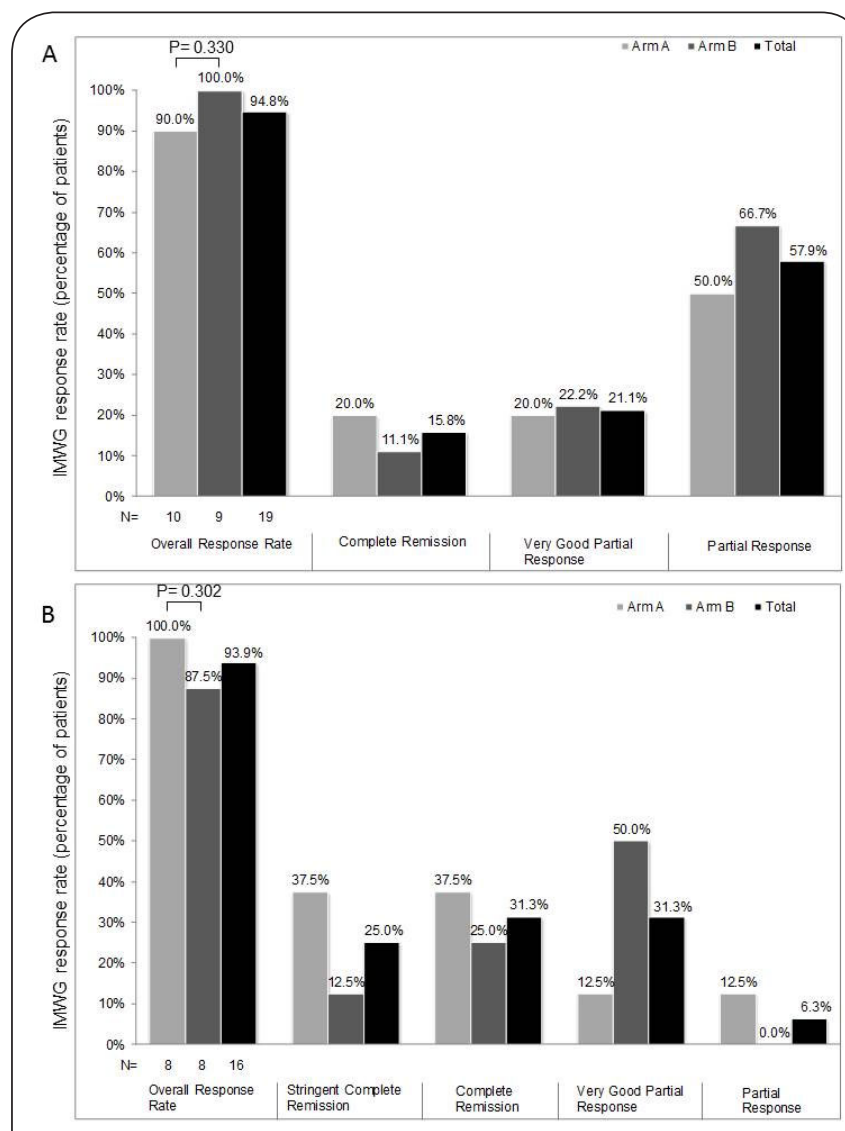

Figure 2. Myeloma response IMWG criteria.

(A) At the end of Induction

(B) At end of ASCT.

E.coli infection, 1 hypothension and 1 exanthema). No exitus occurred during the study.

\section{Discussion}

The main conclusion of the study was that limited lenalidomide exposure before cyclophosphamide based mobilization resulted in adequate grafts to perform a single ASCT could be collected in all patients.

Previous studies, which assessed the impact of lenalidomide treatment upon the mobilization in newly diagnosed MM patients, showed a decrease in the $\mathrm{CD} 34^{+}$cells collected in patients treated with lenalidomide compared to those who received dexamethasone, thalidomide-dexamethasone or vincristine-doxorubicin-dexamethasone (VAD), either with G-CSF or with cyclophosphamide plus G-CSF. Nevertheless, there was no effect on quality of PBSC collected based on similar engraftment across all groups [8]. In our study, we observed similar results. Moreover, the lower blood CD34 ${ }^{+}$ cell counts after lenalidomide exposure can usually be offset by the use of plerixafor [9].

When we focus on the mobilization treatment, results published in different studies [10-13] show that the stem cells 
Huelva et al. Hematology and Leukemia 2018,

http://www.hoajonline.com/journals/pdf/2052-434X-6-4.pdf

collection (among $5.6 \times 10^{6}$ and $8.7 \times 10^{6} \mathrm{CD} 34^{+} / \mathrm{kg}$ depending on the study) is enough when the mobilization is carried out with cyclophosphamide and G-CSF. Our study confirms the effectiveness of this mobilization procedure and although our number of collected progenitors was lower, it was sufficient for the successful transplant. This decrease in the total number of collected stem cells may be motivated by the use of a lower dose of cyclophosphamide $\left(1.5 \mathrm{~g} / \mathrm{m}^{2}\right.$ in our study versus doses of 2 to $4 \mathrm{~g} / \mathrm{m}^{2}$ in the cited studies); as well as the cellular separators yield used in the different sites.

In the present study and despite the limitation of the small number of patients in our series, the RR was comparable with those in other published studies [12-15] with not previously treated MM patients. Due to the limited number of patients who continued maintenance treatment, unfortunately, conclusions cannot be drawn about its usefulness under maintenance in our specific cohort of patients, which is still a controversial issue today [16]. However, the results of the most recent meta-analysis showing a significant OS benefit in patients treated with lenalidomide maintenance argue in favor of establishing lenalidomide maintenance as the standard of care in the post-ASCT setting [17].

Interpretation and comparison of OS and PFS with other studies is hampered by the limited number of patients and current restricted follow-up. It has to be mentioned also, the possibility that the earlier cyclophosphamide administration in arm B, could influence the differential results between arms $A$ and $B$.

As other studies using dexamethasone-lenalidomide in untreated MM patients have previously reported, the regimen was generally well tolerated, with predictable and manageable toxicity. No exitus occurred during the treatment in this study. Our study confirms the results about grafts quality obtained with lenalidomide despite obtaining lower overall yields. Moreover, this study also confirms the effectiveness of mobilization with cyclophosphamide and G-CSF. However, wider randomized studies should confirm the extension and implication of the observations on RR, OS and PFS in the future.

\section{Competing interests}

The authors declare that they have no competing interests.

\section{Authors' contributions}

\begin{tabular}{|l|c|c|c|c|c|c|c|c|c|}
\hline Authors' contributions & FC & ER & MA & JR & AA & AB & JG & GR & AF \\
\hline Research concept and design & $\checkmark$ & $\checkmark$ & $\checkmark$ & $\checkmark$ & $\checkmark$ & $\checkmark$ & $\checkmark$ & $\checkmark$ & $\checkmark$ \\
\hline Collection and/or assembly of data & $\checkmark$ & $\checkmark$ & $\checkmark$ & $\checkmark$ & $\checkmark$ & $\checkmark$ & $\checkmark$ & $\checkmark$ & $\checkmark$ \\
\hline Data analysis and interpretation & $\checkmark$ & $\checkmark$ & $\checkmark$ & $\checkmark$ & $\checkmark$ & $\checkmark$ & $\checkmark$ & $\checkmark$ & $\checkmark$ \\
\hline Writing the article & $\checkmark$ & $\checkmark$ & $\checkmark$ & $\checkmark$ & $\checkmark$ & $\checkmark$ & $\checkmark$ & $\checkmark$ & $\checkmark$ \\
\hline Critical revision of the article & $\checkmark$ & $\checkmark$ & $\checkmark$ & $\checkmark$ & $\checkmark$ & $\checkmark$ & $\checkmark$ & $\checkmark$ & $\checkmark$ \\
\hline Final approval of article & $\checkmark$ & $\checkmark$ & $\checkmark$ & $\checkmark$ & $\checkmark$ & $\checkmark$ & $\checkmark$ & $\checkmark$ & $\checkmark$ \\
\hline Statistical analysis & $\checkmark$ & $\checkmark$ & $\checkmark$ & $\checkmark$ & $\checkmark$ & $\checkmark$ & $\checkmark$ & $\checkmark$ & $\checkmark$ \\
\hline
\end{tabular}

Acknowledgements and funding

Manuscript writing and editorial support was provided by Emili González-Pérez

and Irene Mansilla from TFS Develop. The study was supported by

Asociación Andaluza de Hematología y Hemoterapia and Celgene.

Publication history

Editor: Evangelos Terpos, University of Athens School of Medicine, Greece

Received: 13-Mar-2018 Final Revised: 11-May-2018

Accepted: 14-May-2018 Published: 30-May-2018

\section{References}

1. Bladé J, Cibeira MT, Fernández de Larrea C and Rosiñol L. Multiple myeloma. Ann Oncol. 2010; 21:313-319.

2. Stewart AK, Richardson PG and San-Miguel JF. How I treat multiple myeloma in younger patients. Blood. 2009; 114:5436-43. | Article | PubMed

3. Gertz MA and Dingli D. How we manage autologous stem cell transplantation for patients with multiple myeloma. Blood. 2014; 124:882-90. | Article | PubMed Abstract | PubMed FullText

4. Rajkumar SV, Jacobus S, Callander NS, Fonseca R, Vesole DH, Williams ME, Abonour R, Siegel DS, Katz M and Greipp PR. Lenalidomide plus high-dose dexamethasone versus lenalidomide plus low-dose dexamethasone as initial therapy for newly diagnosed multiple myeloma: an open-label randomised controlled trial. Lancet Oncol. 2010; 11:29-37. | Article | PubMed Abstract | PubMed FullText
5. Kumar S, Giralt S, Stadtmauer EA, Harousseau JL, Palumbo A, Bensinger W, Comenzo RL, Lentzsch S, Munshi N, Niesvizky R, San Miguel J, Ludwig $H$, Bergsagel L, Blade J, Lonial S, Anderson KC, Tosi P, Sonneveld P, Sezer O, Vesole D, Cavo M, Einsele H, Richardson PG, Durie BG and Rajkumar SV. Mobilization in myeloma revisited: IMWG consensus perspectives on stem cell collection following initial therapy with thalidomide-, lenalidomide-, or bortezomib-containing regimens. Blood. 2009; 114:1729-35. | Article | PubMed

6. Greipp PR, San Miguel J, Durie BG, Crowley JJ, Barlogie B, Blade J, Boccadoro M, Child JA, Avet-Loiseau H, Kyle RA, Lahuerta JJ, Ludwig H, Morgan G, Powles R, Shimizu K, Shustik C, Sonneveld P, Tosi P, Turesson I and Westin J. International staging system for multiple myeloma. J Clin Oncol. 2005; 23:3412-20. | Article | PubMed

7. Oken MM, Creech RH, Tormey DC, Horton J, Davis TE, McFadden ET and Carbone PP. Toxicity and response criteria of the Eastern Cooperative 
Huelva et al. Hematology and Leukemia 2018,

Oncology Group. Am J Clin Oncol. 1982; 5:649-55. | PubMed

8. Kumar S, Dispenzieri A, Lacy MQ, Hayman SR, Buadi FK, Gastineau DA, Litzow MR, Fonseca R, Roy V, Rajkumar SV and Gertz MA. Impact of lenalidomide therapy on stem cell mobilization and engraftment post-peripheral blood stem cell transplantation in patients with newly diagnosed myeloma. Leukemia. 2007; 21:2035-42. | Article | PubMed

9. Costa LJ, Abbas J, Hogan KR, Kramer C, McDonald K, Butcher CD, Littleton A, Shoptaw K, Kang Y and Stuart RK. Growth factor plus preemptive ('just-in-time') plerixafor successfully mobilizes hematopoietic stem cells in multiple myeloma patients despite prior lenalidomide exposure. Bone Marrow Transplant. 2012; 47:1403-8. | Article | PubMed

10. Richardson PG, Weller E, Lonial S, Jakubowiak AJ, Jagannath S, Raje NS, Avigan DE, Xie W, Ghobrial IM, Schlossman RL, Mazumder A, Munshi NC, Vesole DH, Joyce R, Kaufman JL, Doss D, Warren DL, Lunde LE, Kaster S, Delaney C, Hideshima T, Mitsiades CS, Knight R, Esseltine DL and Anderson KC. Lenalidomide, bortezomib, and dexamethasone combination therapy in patients with newly diagnosed multiple myeloma. Blood. 2010; 116:679-86. | Article | PubMed Abstract | PubMed FullText

11. Cavallo F, Bringhen S, Milone G, Ben-Yehuda D, Nagler A, Calabrese E, Cascavilla N, Montefusco V, Lupo B, Liberati AM, Crippa C, Rossini F, Passera R, Patriarca F, Cafro AM, Omede P, Carella AM, Peccatori J, Catalano L, Caravita T, Musto P, Petrucci MT, Boccadoro M and Palumbo A. Stem cell mobilization in patients with newly diagnosed multiple myeloma after lenalidomide induction therapy. Leukemia. 2011; 25:1627-31. | Article | PubMed

12. Silvennoinen R, Anttila P, Saily M, Lundan T, Heiskanen J, Siitonen TM, Kakko S, Putkonen M, Ollikainen $H$, Terava V, Kutila A, Launonen K, Rasanen A, Sikio A, Suominen M, Bazia P, Kananen K, Selander T, Kuittinen $\mathrm{T}$, Remes $\mathrm{K}$ and Jantunen $\mathrm{E}$. A randomized phase II study of stem cell mobilization with cyclophosphamide+G-CSF or G-CSF alone after lenalidomide-based induction in multiple myeloma. Bone Marrow Transplant. 2016; 51:372-6. | Article | PubMed Abstract | PubMed FullText

13. Roussel M, Lauwers-Cances V, Robillard N, Hulin C, Leleu X, Benboubker L, Marit G, Moreau P, Pegourie B, Caillot D, Fruchart C, Stoppa AM, Gentil C, Wuilleme S, Huynh A, Hebraud B, Corre J, Chretien ML, Facon $\mathrm{T}$, Avet-Loiseau $\mathrm{H}$ and Attal $\mathrm{M}$. Front-line transplantation program with lenalidomide, bortezomib, and dexamethasone combination as induction and consolidation followed by lenalidomide maintenance in patients with multiple myeloma: a phase II study by the Intergroupe Francophone du Myelome. J Clin Oncol. 2014; 32:2712-7. | Article | PubMed

14. Rajkumar SV, Hayman SR, Lacy MQ, Dispenzieri A, Geyer SM, Kabat B, Zeldenrust SR, Kumar S, Greipp PR, Fonseca R, Lust JA, Russell SJ, Kyle RA, Witzig TE and Gertz MA. Combination therapy with lenalidomide plus dexamethasone (Rev/Dex) for newly diagnosed myeloma. Blood. 2005; 106:4050-3. | Article | PubMed Abstract | PubMed FullText

15. Rosinol L, Oriol A, Teruel Al, Hernandez D, Lopez-Jimenez J, de la Rubia J, Granell M, Besalduch J, Palomera L, Gonzalez Y, Etxebeste MA, DiazMediavilla J, Hernandez MT, de Arriba F, Gutierrez NC, Martin-Ramos ML, Cibeira MT, Mateos MV, Martinez J, Alegre A, Lahuerta JJ, San Miguel J and Blade J. Superiority of bortezomib, thalidomide, and dexamethasone (VTD) as induction pretransplantation therapy in multiple myeloma: a randomized phase 3 PETHEMA/GEM study. Blood. 2012; 120:1589-96. | Article | PubMed

16. Mohty M, Richardson PG, McCarthy PL and Attal M. Consolidation and maintenance therapy for multiple myeloma after autologous transplantation: where do we stand? Bone Marrow Transplant. 2015; 50:1024-9. | Article | PubMed

17. McCarthy PL, Holstein SA, Petrucci MT, Richardson PG, Hulin C, Tosi P, Bringhen S, Musto P, Anderson KC, Caillot D, Gay F, Moreau P, Marit G, Jung SH, Yu Z, Winograd B, Knight RD, Palumbo A and Attal M. Lenalidomide Maintenance After Autologous Stem-Cell Transplantation in Newly Diagnosed Multiple Myeloma: A Meta-Analysis. J Clin Oncol. 2017; 35:3279-3289. | Article | PubMed
Citation:

Huelva FJC, Herranz ER, Rivas MAA, Arredondo JJR, Muñoz AA, García AB, Zamudio JLG, Ramírez GR and Jurado AF. Comparison of two strategies of peripheral blood progenitor cells induction with lenalidomide/ dexamethasone in newly diagnosed multiple myeloma patients, followed by transplantation and lenalidomide maintenance treatment. Hematol Leuk. 2018; 6:4. http://dx.doi.org/10.7243/2052-434X-6-4 